Review Article

www.jestr.org

\title{
Passive Techniques for Fan Noise Reduction in New Turbofan Engines: Review
}

\author{
M.Gorj-Bandpy and M. Azimi*
}

Department of Mechanical Engineering, Babol noshirvani university of Technology

Received 15 September 2012; Accepted 9 March 2013

\begin{abstract}
Among the various environmental concerns, the aircraft noise item has been constantly growing in importance over the past years. Measures for its reduction at the source as well its mitigation around airports must take into account aspects of medicine and technical design as well as legal and land use planning aspects. Fan noise is one of the principal noise sources in turbofan aero-engines. In this paper a review of the main technologies employed for the reduction of fan noise turbofan engines is presented.
\end{abstract}

Keywords: Noise Pollution; Aircraft Noise; Noise Reduction Technologies; Fan noise.

\section{Introduction}

Aircraft noise is second only to road traffic noise in drawing complaints from public about noise pollution. Too much noise obviously impairs our physical and mental existence and therefore it is reasonable to pursue technology assessment concerning noisy technologies. With the global expansion in air travel, aircraft noise has become a major public issue. Therefore, to meet new noise level criteria a lot of effort has been invested by researchers in aero acoustics to reduce noise emissions from aircraft engines. In a typical turbofan engine, fan and exhaust noise [1] are among the major components of the noise signature of an aircraft. The use of large fans and inlet ducts means that fan noise is nowadays one of the principal engine noise sources. In this paper, an overview of major accomplishments from recent researches for fan noise reduction will be given.

\section{Noise propagates from fan}

The passage of air over the aircraft structure or through the power plants causes fluctuating pressure disturbances that propagate to an observer and are perceived as noise. These pressure disturbances are created by airflow discontinuities that occur in the engines, where power generation demands significant changes in pressure and temperature, and on the airframe: high-lift devices and landing gears, as well as the significant wetted area associated with these commercial aircraft, create considerable turbulence.

Ground based perception of engine noise depends to a large extent on the position of the aircraft in relation to its observer. In-flight noise is perceived as a broadband roar, while at approach and take-off the high pitch rotor noise

\footnotetext{
*E-mail address: m_r_azimi1991@yahoo.com

ISSN: 1791-2377 @ 2013 Kavala Institute of Technology. All rights reserved.
}

contributes significantly to the radiated acoustic field [2]. According to Trefny and Wasserbaur [3], "the forwardpropagated fan noise is significant component during takeoff and approach". Tyler and Sofrin [4] noted that, "the discrete frequency compressor Whine is more objectionable than broadband exhaust noise".

The sound that propagates in an aircraft turbofan inlet duct is almost entirely due to the fan. The dominant source of fan tone noise is usually rotor/stator interaction while broadband noise is due to the turbulence [3, 4].

Airport communities bear the full brunt of discrete frequency noise. Specifically, the discrete frequency radiation is a result of the rotor speed, blade number, and the homogeneity of flow field. This section briefly describes some of the currently employed solutions to the problem of fan noise.

\section{Passive techniques}

Noise reduction techniques can be broadly classified as passive and active methods. Passive control involves reducing the radiated noise by energy absorption, while the active method involves reducing source strength or modifying acoustic field in the duct to obtain noise reduction.

Example of these technologies will be presented include swept and leaned stators, bifurcated inlet, acoustic treatment placed over the fan.

\subsection{Swept and leaned}

A primary generating mechanism of forward-radiated fan noise is stator/rotor interaction. Many of the modern fan designs use fan sweep near the tip to reduce aerodynamic losses associated with shocks and improve stall margin. There is also evidence that additional mass flow through the fan can be achieved. The designs were aggressive and some experienced part-speed flutter problems. Swept stators have been found to reduce fan noise by increasing the phase 
changes from hub-to-tip of the unsteady aerodynamics producing the sound and by increasing the effective distance from the fan to the stator vanes. The three most common types of interaction are rotor blades chopping through the wakes of upstream stators, wakes from rotor blades impinging on downstream stators, and the pressure fields of the rotors reflecting nearby objects. The most important one is generated as a result of periodic impingement of fan wakes on the outlet guide vanes (OGV) [5].

Rotor-stator interaction noise is caused by the periodic cutting of rotor wakes by the stator vanes. The strength of the interaction is related to the efficiency with which unsteady pressure distribution on the vanes couples to the acoustic modes of the bypass duct [6]. The pressure distribution, in turn, depends on the upwash, induced by the rotor wake on the stator. Through this dependence, the source strength is strongly influenced by the spanwise phase of the upwash [7]. Significant upwash phase variation can cause noise cancellation between contributions from different locations along the vane span resulting in weaker interaction tones. For the most part, variation in the spanwise phase of the upwash is controlled by the number of individual rotor wakes that intersect a given vane. This number is determined, primarily, by the kinematics of the rotor wakes in relation to the stator vanes. Swirl variation from hub to tip introduces a tangential shift between the circumferential positions of the wakes along the span. The shift increases with downstream distance causing the tip wakes to advance ahead of the hub wakes. Sweep is defined as the axial displacement of the vane leading edge from its baseline position. Similarly, lean is defined as the circumferential displacement of the vane leading edge from its baseline position. Generally, this shift becomes large enough that wake sheets from more than one blade intersect a single vane. When chosen properly, sweep and/or lean reduce rotor-stator interaction tone noise. To reduce noise, sweep and lean must be chosen in such a way so as to increase wake intersections per vane [5]. Since the early '70s, several theoretical and experimental studies have hinted at the potential of sweep and lean for reducing rotorstator tone noise [8-15]. In a more recent experimental study, the benefits of OGV sweep and lean for reducing fan noise were convincingly demonstrated for a representative modern low-speed fan stage [16]. The results show that, compared to the radial one, swept and leaned OGV provides sizable reductions in the level of rotor-stator interaction tone noise for a wide range of operating conditions. A set of simple design rules is proposed for implementing sweep and lean in practical fan stage geometries. Sweep for which the vane tip is downstream of its root, and lean in the direction of the fan rotation reduce the strength of the interaction tones with size of reduction dependent on the amount of sweep and lean chosen [5].

\subsection{Acoustic liner}

Probably the most common passive method of noise control is the use of acoustic liners. The liners absorb the radiated acoustic energy, thereby reducing the far-field noise levels. The acoustic liner may cover most of the available surface, both in the inlet and exhaust ducts, as resulting from an optimization procedure involving antagonist factors like the installation of anti-icing systems. Liners are usually manufactured in sections which each cover part of the duct's circumference. This facilitates the manufactured and installation of the lining inside the nacelle. The sections are joined together by longitudinal strips or splices. The splices will be acoustically hard. This means that there will be discontinuities in the acoustic impedance around the circumference of the duct. The types of acoustic liners are typically locally reacting cavity linings. The specific acoustic impedance of these types of liners depends on the properties of the lining, the mean flow and the frequency of the sound. In general, it is more difficult to attenuate the fan tones as the engine power is increased, notably at high supersonic fan speeds. However use of liners increases the engine weight, which is undesirable. Also future developments will see increase in bypass ratio, while the inlet length is not scaled with diameter. This will make liners less effective. Their performance is always limited by their confined length, in particular when aero engines are considerable where multiple dominant tones are related to buzz-saw noise or rotor-stator interaction noise.

The concept of non-uniform liners has been studied by several authors: Lasing and Zarumski [17] appears to be the first publishe work on the type of axially segmented liner, using mode-matching techniques. This type of axially segmented liner is of interest because it could be used to increase the attenuation of fan tones at high supersonic fan speeds. Unruh [18] first examined how the liner's length, as well as its impedance, may be tuned to optimize the attenuation. Also, both baumeister [19] and Tsai [20] realized that the first segment of lining acts as a scatterer, which facilitates the attenuation of the sound in adjacnt lined segments. However, Baumeister concluded that the use of optimized axially segmented liners fails to offer sufficient advantage over a uniform liner to warrant their use except in low-frequency, single-mode application.

The name "buzz-saw" noise or multiple pure tones is generally used to describe this component of fan noise. "Buzz-saw" noise is radiated from a turbofan inlet duct when the fan tip speed is supersonic. McAlpine et al [21] showed that the principal sources of buzz-saw noise is not always the rotor-alone pressure field. Non rotor-alone scattered tones can be a significant source of buzz-saw noise at low supersonic fan speeds. "Buzz-saw" noise is the principal tone noise source radiated from a turbofan inlet duct at supersonic fan speeds. The noise source consists of a set of tones, known as engine orders (EO) that are harmonics of the engine's shaft rotation frequency. These EO tones are the buzz-saw noise. The level of the scattered modes can be significantly reduced by having the buzz-saw noise. The level of the scattered modes can be significantly by having thinner splices. However, at sideline, the rotor-alone filed is well cut-on. At this fan speed, the rotor-alone modes are predicted to remain the principal fan tones noise source. The level of the scattered modes at sideline can be reduced with thinner splices. However, at high fan speeds, thinner splices are not predicted to lead to an increase in the overall sound power transmission loss. This is because the rotor-alone pressure field is well cut-on, and poorly absorbed by the duct liner. At high fan speeds, more novel noise control methods are required to significantly improve the attenuation.

\subsection{Bifurcated inlet}

A bifurcated two-demisional (2-D) supersonic inlet is one of the several inlets being considered. The bifurcated 2-D inlet design incorporates a rectangular inlet opening that gradually changes to a circular cross-section at the fan face. The bifurcated ramp or splitter plate center body body is adjustable to obtain the appropriate shock wave conditions with the inlet for the engine at transonic and supersonic 
flights. With the adjustable center body, the flow condition at the fan face can also be controlled at a subsonic condition. The bifurcated 2-D inlet also incorporates inlet guide vanes right in front of the fan face.

An older version of a bifurcated 2-D supersonic inlet, designed by NASA was tested by wagner [22]. The NASAdesigned bifurcated 2-D inlet did not have inlet gide vanes (IGV). Since the tests were conducted at ground-static conditions and the inlet did have a bellmouth a significant boundary layer separation was recorded at the cowl lip. Miller [23] made continued effort to examine the performance of the NASA-designed bifurcated 2-D inlet without IGV. His tests were ground-static too but conducted with bellmouth to reduce the cowl lip boundary layer separation. Both work documented the aeroacoustic and aerodynamic performance of the bifurcated 2-D supersonic inlets at two different fan speeds. Comparisons were made between the performances of the bifurcated 2-D supersonic inlets and the axisymmetric supersonic inlets. Hanuska [24] conducted another aeroacoustic experiment for a new bifurcated 2-D supersonic inlet with IGV. This bifurcated 2D supersonic inlet, designed recently by Boeing Company, differed from the old NASA designed inlet in that Boeing bifurcated 2-D supersonic inlet had IGV. In Haniska's work [14], the concern was to evaluate the use of flat plate IGV and airfoil IGV on the effects of "soft chocking" to reduce noise. Resulted by Li ett al [25] showed that varying the distance between the trailing edge of the bifurcated ramp of the inlet and the fan face had negligible effect on the total noise level. However, the effect of inlet guide vanes (IGV) axial spacing to the fan face has a first order effect on the aero acoustic for the bifurcated 2-D inlet. As much as $5 \mathrm{~dB}$ reduction in the overall sound pressure level and as much as $15 \mathrm{~dB}$ reduction in the blade passing frequency tone were observed when IGV was moved from 0.8 chord of rotor blade upstream of the fan face to 2.0 chord of the blade upstream.

\section{Conclusions}

Engine noise is one of the major contributors to the overall sound levels as aircraft operate near airports. On the other hand, turbofan engines are commonly used on the commercial transports due to their advantage for higher performance and lower noise. Significant progress continues to be made with noise reduction for turbofan engines.

In this paper a review of the main established technologies for fan reduction and those currently under evaluation is also presented. We believe that this will be particularly useful, for instance, to assess the influence of a fan noise mitigation device on the aircraft operating cast.
1. Gorji-Bandpy, M., Azimi, M. 2012, Technologies for Jet Noise Reduction in Turbofan Engines, Aviation, DOI:10.3846/16487788.2012.679770.

2. Rao, Nikhil M., April 1999, Reduction of Unsteady Stator-Rotor Interaction by Trailing Edge Blowing Using MEMS Based Microvalves, M.S. thesis, Blacksburg, Virginia.

3. Trefney, C.J., Wasserbauer, J.W., 1986, Low-speed Performance of an Axisymmetric, Mixed-Compression, Supersonic Inlet With Auxiliary Inlets, NASA TP-2557, February.

4. Tyler, J. M., and sofrin, T.G., 1962, Axial Compressor Noise Studies, SAE Transactions, Vol.70.

5. Envia, E., Nallasamy, M., December 1998, Design selection and analysis of a swept and leaned stator concept, NASA/TM-1998208662.

6. Groeneweg, J.F., and Sofrin, T.G., Gliebe, P.R., August 1991, and Rice, E.J., Turbomachinary Noise, in Aeroacoustics of Flight Vehicles: Theory and Particle, Volume 1: Noise Sources, Edited by H.H. Hubbard, NASA RP-1258, Vol.1 WRDC Technical Report 903052.

7. Envia, E., Huff, D.L. and Morfison, C.R., May 1996, Analytical Assessment of Stator sweep and laen in Reducing Rotor-Stator Tone Noise, AIAA Paper 96-1791.

8. Rao, G.V.R., January 1972, Use of Leaning Vanes for Fan Noise Reduction, AIAA Paper 72-126.

9. Kazin, S.B., November 1973, Radially Leaned Outlet Guide Vanes for Fan Source Noise Reduction, NASA-CR 134486.

10. Adamczyk, J.J., 1974, Passage of a Swept Airfoil Through an Oblique Gust, Journal of Aircraft, Vol.11, pp.281-287

11. Hayden, R.E., Bliss, B.B., Murray, B.S., Chandiramani, K.L., Smullin, J.I. and Schwaar, P.G., December 1977, Analysis and Design of High Speed, Low Noise Aircraft Fan Incorpating Swept Leading Edge Rotor and Stator Blades, NASA CR-135092.

12. Schultenm J.B.H.M., 1982, Sound Generated by Rotor Wakes Interacting with a Leaned Vane Stator, AIAA Journal, Vol. 20, No.10, pp. 1352-1358.

\section{References}

13.Envia, E., and Kerschen, E.J., October 1984, Noise Produced by Interaction of a Rotor Wake with swept Stator Blade, AIAA Paper 842326.

14. Envia, E., and Kerschen, E.J., July 1986, Noise Generated by convected Gusts Interacting With Swept Airfoil Cascade, AIAA Paper 86-1872.

15. Envia, E., and Kerschen, E.J., December 1990, Influence of Vane Sweep on Rotor-Stator Interaction Noise, NASA-CR 187052.

16. Woodward, R.P., Elliott, D.M., Hughes, C.E. and Berton, J.J., October 1997, Benefits of Swept and Leaned Stators for Fan Noise Reduction, NASA-TM (TBD).

17. Lansingm D.L., Zorumski, W.E., 1973, Effects of wall admittance changes on duct transmission and radiation of sound, Journal of Sound and Vibration, Vol.27, pp.85-100.

18. Unruh, J.F., 1976, Finite Length tunning for low-frequency lining design, Journal of Sound and Vibration, 45 (1), 5-14.

19. Baumeister, K.J., 1979, Evaluation of optimized multisectioned acoustic liners, AIAA Journal, 17 (11), 1185-1192.

20. Tsai, M.S., 1982, Mode scattere design for fan noise suppression in two-dimensional ducts, Journal of Sound and Vibration, 83 (4) 501512.

21. Mcalpine, A., Wrigh, M.C.M., 2006, Acoustic scattering by a spliced turbofan inlet duct liner at supersonic fan speeds, Journal of Sound and Vibration, 292, 911-934.

22. Wangger, R., 1995, Aeroacoustics of the bifurcated 2 D supersonic inlet, Masters Thesis, viriginia Polytechnique Institue and State university.

23. Miller, K.C., 1996, Comparison of the aeroacoustics of two smallscale supersonic inlets Masters Thesis, Virginia polytechnique institute ans State university.

24. Hanuska, C.A., 1998, Aeroacoustic effect of choking at inlet guide vanes in subsonic and supersonic inlets, Masters Thesis, Virginia Polytechnique Institue and State university.

25. LI, S.M., Hanuska, C.A, and Ng, W.F., 2001, An experimental investigation of the aeroacoustics of two-demisional bifurcated supersonic inlet, Journal of Sound and Vibration., 248 (1), 105-121. 